\title{
INVESTIGAÇÃO DE POSSÍVEIS OBSTRUÇÕES SÍLICO-ALUMINOSAS EM TECIDOS CONDUTORES EM PinUs caribaea VAR. HONDURENSIS RELACIONADAS À SENESCÊNCIA E MORTE DE PLANTAS ${ }^{1}$
}

\author{
Lucélia Parreira Vasconcelos², Gilberto Fernandes Correa ${ }^{3}$ e Lísias Coelho ${ }^{3}$
}

\begin{abstract}
RESUMO - Com base na hipótese de que polímeros associados a silício (Si) estariam obstruindo traqueídeos, e assim contribuindo para um colapso nutricional de maciços florestais de Pinus caribaea, tropicais em áreas de cerrado, nos chapadões das regiões do Triângulo Mineiro e do Alto Paranaíba (MG), foi desenvolvido este trabalho. Estudos precedentes mostraram uma relação estreita deste quadro fisiológico com deficiências nutricionais. Sabe-se, no entanto, que as sementes usadas na implantação desses maciços apresentavam grande variabilidade genética bem expressa na diversidade de comportamento das plantas, uma vez que parte delas permanece sadia enquanto outras entram em processo de senescência de intensidade variável, culminando com a morte da planta. Neste estudo, foram amostrados segmentos de raízes e do ponteiro de plantas aparentemente normais (acículas verdes), em diferentes estágios de senescência (acículas amareladas) e mortas. Essas amostras, após secagem até o ponto crítico, foram observadas em um microscópio eletrônico de varredura acoplado de uma microssonda de raios-X. Constatou-se a presença de Si e Al nos tecidos do xilema e do floema, tanto na parte aérea quanto nas raízes, e os maiores teores foram encontrados no xilema das raízes. Todavia, não foi constatada obstrução ou qualquer presença de corpos sílico-aluminosos nos tecidos condutores das partes analisadas. Verificou-se, no entanto, que a presença de Si em associação ao Al ocorreu segundo uma relação Al/Si da ordem de 2,6. Os dados revelaram ainda que a amplitude de variação do Si é de 1,5 vez maior que a do Al. Concluiu-se que a amplitude de variação do Si é maior que a do Al, estabelecendo uma relação de variação (Si-Al).
\end{abstract}

Palavras-chave: Pinus, Doença abiótica, Solo fase cerrado e Silvicultura.

\section{INVESTIGATION OF POSSIBLE SILICON-ALUMINIUM OBSTRUCTIONS IN THE VASCULAR BUNDLE IN Pinus caribaea VAR. Hondurensis RELATED TO PLANT SENESCENCE AND DEATH}

\begin{abstract}
This work was carried out based on the hypothesis that polymers associated with silicone (Si) would be obstructing tracheid, therefore contributing to a nutritional collapse of Pinus caribaea forest bulks, in the Triângulo Mineiro and Alto Paranaíba (MG) plains. Previous studies showed a narrow relationship between these physiologic patterns with nutritional deficiencies. However, it is known that seeds used in the establishment of these bulks presented great genetic variability well expressed in diversity of plant behavior, inasmuch as part of them remains healthy and the others start a changeable intensity senescence, which ends up in the death of the plant. In this study, it was sampled segments of root and apical shoots of apparently normal (green needles) plants at different senescence stages (yellow needles) and dead plants. Those samples, after being dried until critical point, were observed by scanning electron microscope coupled to an $X$-ray microprobe. It was noted the presence of Si and Al in xylem and phloem tissues in the aerial section as well as in the roots, and the greatest contents were found in xylem of the plants. However, it was not observed any obstruction or any presence of Si-Al bodies in the conducting tissues of the analyzed parts. But, it was observed that the presence of Si associated to Al occurred according to a 2.6 order Al/Si ratio. Data also revealed that Si variation amplitude is 1.5 times greater than the Al variation amplitude. It concluded that Si variation amplitude is greater than the one of $\mathrm{Al}$, which establishes a variation relationship (Si-Al).
\end{abstract}

Key words: Pine tree, Abiotic disease, Savannah phase soil and Silviculture.

\footnotetext{
${ }^{1}$ Recebido em 16.09.2008 e aceito para publicação em 18.04.2011.

${ }^{2}$ Instituto Mineiro de Agropecuária, IMA, Brasil. E-mail: <luceliaparreira@yahoo.com.br>.

${ }^{3}$ Universidade Federal de Uberlândia, UFU, Brasil. E-mail: <gfcorrea@ufu.br> e <lisisas@iciag.ufu.br>.
} 


\section{INTRODUÇÃO}

A necessidade no aumento da produção de derivados das florestas trouxe fortes tendências para mudanças significativas na forma de uso da terra, com a adoção de sistemas produtivos sustentáveis, utilizando espécies exóticas de rápido crescimento, principalmente pertencentes aos gêneros Pinus e Eucalyptus.

Implantados principalmente no início da década de 70, os maciços florestais de Pinus situam-se, em geral, nos chapadões extensamente dominados por Latossolos de textura muito argilosa e caráter ácrico (EMBRAPA, 2006). Há, portanto, limitações de ordem pedológica, que, se não consideradas no manejo florestal, constituem ou induzem condições que podem estar na origem de problemas nutricionais, que estariam levando os pinheiros a um processo de senescência precoce em relação às plantas arbóreas (CHAVES, 2002).

Atualmente, o melhoramento das espécies objetiva atender finalidades industriais, como produção volumétrica, árvores com fustes mais retos, menor número de bifurcações, menor número de galhos grossos, celulose de fibra longa, visando papel de boa qualidade, maior volume de madeira serrada e extração de resina em maior volume (RESENDE; HIGA, 1994).

O problema da morte precoce de pinheiros tropicais tem chamado a atenção de setores empresariais e da pesquisa na região oeste de Minas Gerais. O sintoma nos pinheiros consiste no amarelecimento das acículas, que ocorre da ponta para a base, evoluindo para um tom pardo-avermelhado. Esses sintomas são mais severos na parte superior da copa. O amarelecimento se intensifica na planta, levando à queda das acículas, à morte e a posterior queda do pinheiro (CHAVES; CORRÊA, 2003). Essas sintomatologias ocorrem distribuídas de forma aparentemente aleatória nos talhões, tanto em árvores dominadas como em dominantes (CHAVES; CORRÊA, 2005).

Postula-se que a senescência precoce de plantas de Pinus caribaea var. hondurensis tenha relação com a obstrução de traqueídeos em tecidos da parte aérea e ou de raízes, ocasionada por compostos sílicoaluminosos. Assim, o objetivo desse trabalho foi estudar possíveis associações sílico-aluminosas em traqueídeos de Pinus caribaea var. hondurensis, em plantas sadias e em plantas que apresentam diferentes estágios de senescência, ocasionando a morte precoce de pinheiros, em áreas do Triângulo Mineiro e Alto Paranaíba.

\section{MATERIAL E MÉTODOS}

As áreas amostradas compreenderam talhões de Pinus caribaea var. hondurensis em idade comercial, apresentando pinheiros com sintomas bem característicos de senescência. Foram utilizados dois locais de amostragem: áreas I (pertencente à empresa Satipel Industrial S.A., compreendendo áreas da região do Alto Paranaíba, oeste de Minas Gerais), e II (localizada também no oeste de Minas Gerais, na região do Triângulo Mineiro, pertence à empresa Pinusplan Reflorestamento Ltda.). As áreas estudadas situam-se entre 900 e 970 m de altitude, com predominância do tipo climático Cwa, clima quente, inverno seco, temperatura média acima de $22^{\circ} \mathrm{C}$ no mês mais quente e abaixo de $18^{\circ} \mathrm{C}$ no mês mais frio, além de menos de $30 \mathrm{~mm}$ de chuva no mês mais seco. As regiões das áreas amostradas apresentam-se entre as latitudes 18 e $19^{\circ} \mathrm{S}$ e longitudes 47 e $49^{\circ} \mathrm{W}$ (MIRANDA, 2005).

Primeiramente, foram percorridos talhões em idade comercial de corte para a seleção dos pinheiros a tombar, contemplando plantas com aparência normal (com acículas verdes intenso) até aquelas com visível processo de senescência em graus variados, desde poucas acículas amarelas até ausência de acículas (plantas mortas). A coleta dos indivíduos das diversas classes foi aleatória, desde árvores próximas até outras mais distantes (Figura 1).

Posteriormente, foram identificados todos os pinheiros escolhidos para o estudo. Características relacionadas às dimensões (altura total, altura da primeira inserção e DAP) não foram analisadas. As plantas foram amostradas de acordo com a coloração prevalescente das acículas (Tabela 1).

Na área I foram coletados seis ponteiros (extremidade da copa) para cada um dos estágios pré-definidos, após o abate das árvores. Na área II, coletaram-se seis raízes para cada estágio, conforme definido na Tabela 1 , perfazendo um total de 60 plantas amostradas nas duas áreas, afim de analisar caso houvesse bloqueio de seiva, se este seria na parte aérea ou no sistema radicular.

Num primeiro momento, houve a secagem ao ponto crítico de treze amostras escolhidas ao acaso, etapa também conhecida como fase de desidratação, em aparelho marca Bal-Tec, modelo CPD 030. Após esta etapa inicial, as treze amostras foram analisadas mediante microscopia eletrônica de varredura (MEV). As demais amostras ficaram acondicionadas em geladeira para futuras análises devido à inviabilidade econômica. 

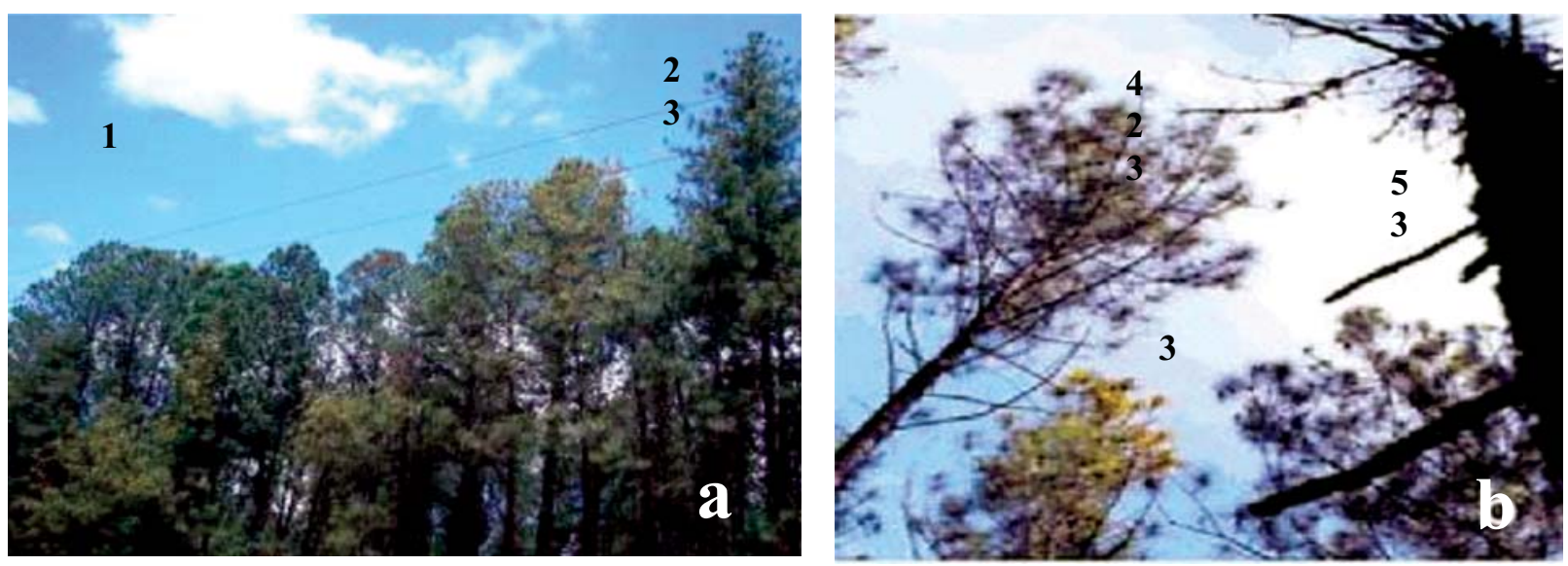

Figura 1 - Talhão de Pinus caribaea var. hondurensis mostrando o critério utilizado na escolha das árvores a serem estudadas. Plantas de Pinus caribaea nos estágios 1 e 2 (a) e nos estágios 3, 4 e 5 (b) revelando as diferentes classes de coloração de copa.

Figure 1 - Plot of Pinus caribaea var. hondurensis showing the criteria used in choosing the trees to be sampled. Plants of Pinus caribaea in stages 1 and 2 (a) and in stages 3, 4 and 5 (b) showing the different classes of crown colouring.

Tabela 1- Estágios e descrição das respectivas características das plantas amostradas. Table 1 - Relationships and description of the characteristics of the sampled plants.

\begin{tabular}{cl}
\hline Estágios & Característica da planta \\
\hline 1 & aparentemente normal, com acículas de coloração verde intenso \\
2 & acículas de coloração verde-amarela \\
3 & acículas de coloração amarela \\
4 & acículas amarelas e acentuada perda destas \\
5 & morta \\
\hline
\end{tabular}

\section{RESULTADOS E DISCUSSÃO}

O procedimento analítico ao microscópio eletrônico de varredura (MEV) iniciou-se em amostras da parte aérea de plantas normais (estágio 1) (Figura 2). Observou-se que tanto o $\mathrm{Al}$ como o Si ocorrem em quantidades variáveis, principalmente no floema (Tabela 2), apresentando uma relação $\mathrm{Al} / \mathrm{Si}$ em torno de 2,6. Há, portanto, em todos os tecidos analisados, menor teor de Si em relação ao Al. Nota-se que, no xilema da parte aérea, os teores de $\mathrm{Si}$ e $\mathrm{Al}$ são maiores do que no floema para plantas no estágio 1 (Tabela 2).

Também pode-se observar que nas estruturas que foram denominadas nódulos, encontradas no floema, os teores de Si e Al foram maiores do que aqueles encontrados na parede desta estrutura condutora (floema).
Nota-se, neste estudo, que quando o teor de Si é maior, o de Al o acompanha, particularmente, no sistema radicular (Tabela 2). A respeito desses dois elementos, Hodson e Sangster (1999) afirmam que, nas espécies da ordem Coniferae, o Si é sempre depositado conjuntamente com o alumínio, preferencialmente na epiderme das acículas e nos elementos vasculares. Segundo os mencionados autores, a deposição conjunta com o Si seria um mecanismo de isolar o Al tóxico na planta.

O Al presente na parte aérea é neutro, conforme afirma Grassi Filho (2006), e sua presença deve ocorrer principalmente em tecidos não fotossintéticos, conforme afirma Chaves (2002), referindo-se a plantas de Pinus caribaea. Portanto, é de se esperar, segundo este autor, que o Al se concentre no floema e, em contrapartida, seriam muito baixos os teores deste elemento no xilema. 


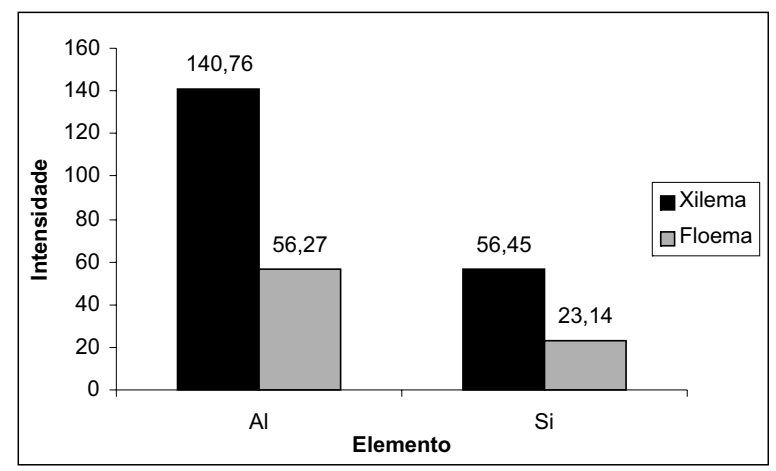

Figura 2 - Proporção de Al e Si em tecidos (xilema e floema) da parte aérea em planta de Pinus caribaea var. hondurensis sadia (estágio 1).

Figure 2 - Proportion of Al and Si in tissues (xylem and phloem) of the shoot of a Pinus caribaea var. hondurensis plant (stage 1).

Essas considerações evidentemente não estão levando em conta a possibilidade da precipitação do Al com o Si, hipótese que está sendo ponderada neste estudo.

Em face desta constatação preliminar, as análises foram, então, direcionadas para a situação extrema, isto é, a parte aérea de plantas mortas (estágio 5). Nestas, contrariando o esperado, não foi encontrado acúmulo de $\mathrm{Al}$ e ou $\mathrm{Si}$, razão pela qual se desprezou a análise quantitativa (Figura 3). Não é dada uma explicação para esses resultados supostamente contraditórios, uma vez que tais elementos tendem a se concentrar em determinados tecidos.

Analisadas as amostras relativas à parte aérea, abrangendo estágios extremos (1 e 5) que apresentam resultados supostamente contraditórios, direcionaram-se as demais análises para tecidos da raiz. Foram analisados os estágios senescentes 2, 3 e 4, bem como a classe 5 (planta morta). Observou-se no xilema radicular de plantas nos estágios 2, 3 e 4 que os teores de Si e $\mathrm{Al}$ foram maiores do que aqueles encontrados no floema, em coerência com a hipótese de trabalho. Os dados apresentados na tabela 2, embora de grandeza variável, geram relações $\mathrm{Al} / \mathrm{Si}$ relativamente estáveis, em torno de 2,6, conforme já observado para a parte aérea. Depreende-se, em concordância com a literatura (HODSON; SANGSTER, 1999), que se o Si exerce a função de imobilizar o Al, num mecanismo de isolamento de Al tóxico na planta, isso deve ocorrer no início do fluxo, portanto no xilema.

De forma coerente, observa-se que nas análises direcionadas à parede do xilema e do floema em raízes - por exemplo: estágio 4 (Figura 4) - os teores de Si e Al apresentam-se maiores no xilema. No entanto, frente ao fato de não se ter encontrado qualquer obstrução de traqueídeos por deposição de silício e alumínio nas partes analisadas, os resultados sugerem que, se este

Tabela 2- Teores de Al, Si e relação Al/Si no material de plantas normais, em senescência e mortas de Pinus caribaea var. hondurensis nas duas áreas amostradas.

Table 2 - Contents of Al, Si and respective Al / Si in the material of normal plants, and killed in senescence of Pinus caribaea var. hondurensis in the two areas sampled.

\begin{tabular}{lccc}
\hline TECIDOS CONDUTORES & ESTÁGIOS & Al & Relação Al/Si \\
\hline 1. ponteiros & & & 5,52 \\
Xilema (parede) & 1 & 12,83 & 1,97 \\
Floema (nódulo) & 1 & 5,65 & 1,36 \\
Floema (parede) & 1 & 3,56 & 2,32 \\
& & & 4,59 \\
2. raízes & & 12,22 & 3,81 \\
Xilema (parede) & 4 & 11,20 & 2,31 \\
Floema (nódulo) & 2 & 6,38 & 2,96 \\
Floema (nódulo) & 3 & 3,89 & 2,7 \\
Floema (parede) & 4 & 6,99 & 3,59 \\
Floema (parede) & 5 & 21,44 & 2,39 \\
Floema (nódulo) & 5 & 9,82 & 2,18 \\
\hline
\end{tabular}

1 planta aparentemente sadia (normal), com acículas de coloração verde intenso.

2 planta com acículas de coloração verde-amarela.

3 planta com acículas de coloração amarela.

4 planta com acículas amarelas e acentuada perda destas.

5 planta morta.

Revista Árvore, Viçosa-MG, v.35, n.3, Edição Especial, p.627-632, 2011 

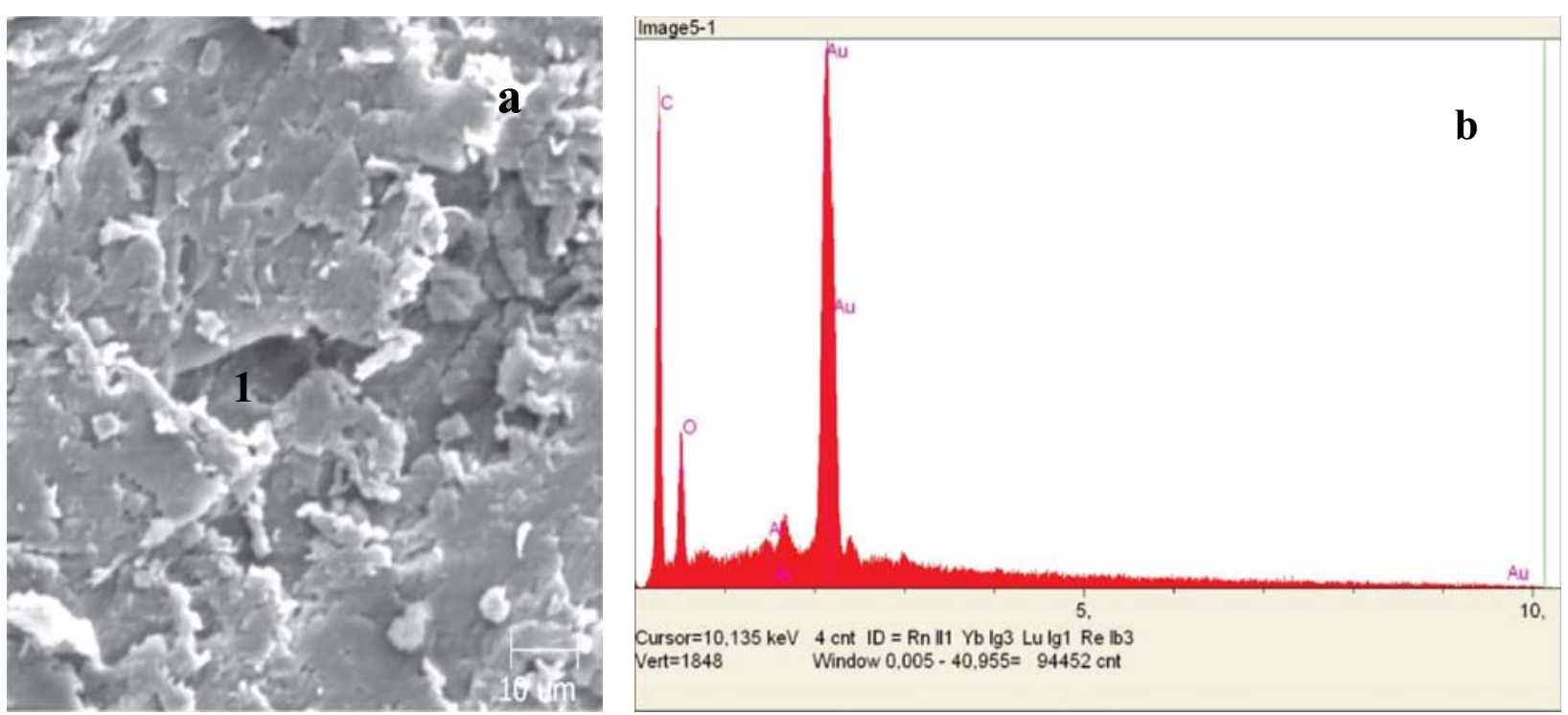

Figura 3 - Micrografia de tecidos do lenho (a) correspondente ao ponteiro da copa de uma planta morta (estágio 5), com indicação do ponto (1) analisado pela microssonda de raios-X e respectivo espectro (b), revelando virtual ausência de Al e Si.

Figure 3 - Micrography tissues of the wood (a) equal to the pointer of the crown of a dead plant (stage 5), indicating the point (1) examined by the X-ray microprobe and its spectrum (b), showing virtual absence of Al and Si.

processo ocorre no gênero Pinus, sua possível constatação deve aparecer nos tecidos condutores no início do fluxo, isto é, nos pêlos radiculares e radicelas. Embora este estudo não tenha focado esses tecidos condutores iniciais, sugere-se, dentro desta linha de pesquisa, a necessidade de investigar, de forma similar, os tecidos condutores no início do sistema radicular.

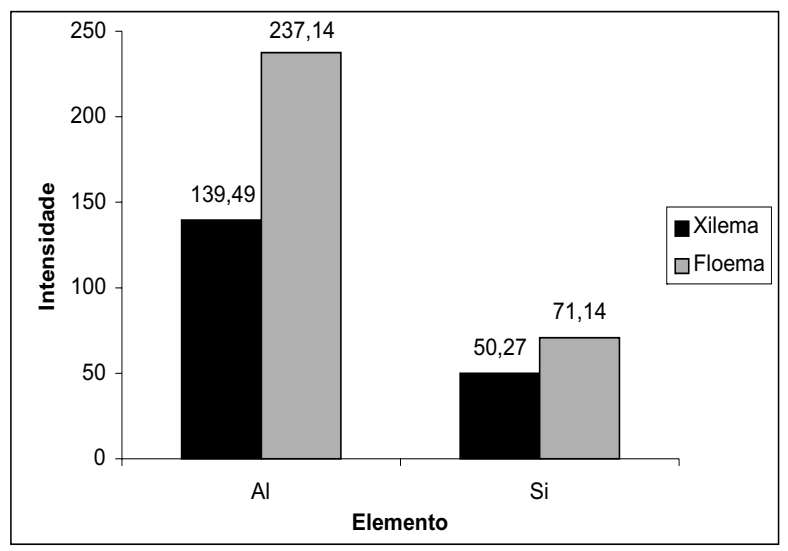

Figura 4 - Proporção de Al e Si no xilema e no floema de raiz em planta no estágio de senescência 4.

Figure 4-Proportion of Al and Si in the xylem and phloem of a plant root in the stage of senescence 4.
Apesar dos dados disponíveis não serem conclusivos (poucas análises), eles sugerem que, de modo geral (parte aérea e raiz), quando a quantidade de Al é maior, o Si é proporcionalmente ainda maior, fornecendo uma relação Al/Si mais baixa (Tabela 2 estágios 1 e 4). Por outro lado, quando o tecido apresenta pouco $\mathrm{Al}$, a quantidade de Si é proporcionalmente ainda menor, gerando uma relação $\mathrm{Al} / \mathrm{Si}$ maior (estágio 4 Tabela 2). Portanto, a amplitude de variação do Si é maior que a do Al. Enquanto para o Si o fator de variação é de 9 vezes (variação de 9,8 a 1,1), para o Al este fator é 6 (variação de 21,4 a 3,6), o que estabelece uma relação entre eles de 1,5.

É provável que a hipótese inicial seja válida, embora não confirmada neste estudo. Porém, pesquisa similar deve ser direcionada às extremidades do sistema radicular: pêlos absorventes e radicelas, além da possibilidade deste mesmo estudo ser também realizado em condições controladas.

\section{CONCLUSÃO}

Nas populações de Pinus estudadas, não foi verificada obstrução de tecidos condutores (traqueídeos) na parte aérea e/ ou em raízes, mediante a deposição conjunta de Si e Al.

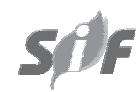

Revista Árvore, Viçosa-MG, v.35, n.3, Edição Especial, p.627-632, 2011 
Embora o Al seja abundante em relação ao Si, observa-se que quando o teor de Al é mais elevado, proporcionalmente o de Si é ainda maior e, por outro lado, quando o teor de Al é menor, o de Si é proporcionalmente ainda menor. Isso faz com que a amplitude de variação do Si seja maior que a do $\mathrm{Al}$, estabelecendo uma relação de variação (Si-Al).

\section{AGRADECIMENTOS}

Às empresas Satipel Industrial S.A. e Pinusplan Reflorestamento Ltda., pela oportunidade de desenvolver este estudo.

\section{REFERÊNCIAS}

CHAVES, R. Q. Relações solo-planta em povoamentos de Pinus caribaea Morelet com indivíduos manifestando amarelecimento das acículas seguindo de definhamento e morte. 2002. $100 \mathrm{f}$. Dissertação (Mestrado em Solos) - Instituto de Ciências Agrárias, Universidade Federal de Uberlândia, Uberlândia, 2002.

CHAVES, R. Q.; CORRÊA, G. F. Micronutrientes no Sistema solo-Pinus caribaea Moret em plantios apresentando amarelecimento das acículas e morte de plantas. Revista Árvore, v.27, n.6, p.769-778, 2003.
CHAVES, R. Q.; CORRÊA, G. F. Macronutrientes no sistema solo-Pinus caribaea Moret em plantios apresentando amarelecimento das acículas e morte de plantas. Revista Árvore, v.29, n.5, p.691-700, 2005.

EMPRESA BRASILEIRA DE PESQUISA AGROPECUÁRIA - EMBRAPA. Centro Nacional de Pesquisas de Solos. Sistema brasileiro de classificação de solos. 2.ed. Rio de Janeiro, Embrapa Solos, 2006.

GRASSSI FILHO, H. Cobalto, sódio, silício e alumínio. Botucatu: Universidade Estadual Paulista, 2000.

HODSON, M. J.; SANGSTER, A. G. Aluminium/silicon interactions in conifers. Journal of Inorganic Biochemistry, v.76, n.1, p.89-98, 1999.

MIRANDA, E. E. (Coord.). Brasil em relevo. Campinas: Embrapa Monitoramento por Satélite, 2005. Disponível em: http://www.relevobr.cnpm.embrapa.br. Acesso em: 24 jul. 2007.

RESENDE, M. D. V.; HIGA, A. R. Estimação de valores genéticos no melhoramento de Eucalyptus: seleção em um caráter com base em informações do individuo e seus parentes.

Boletim de Pesquisa Florestal, n.28/29, p.11-36, 1994. 